\title{
Brachial plexus injury: are we doing enough?
}

Amit Thapa , Bidur KC , Bikram Shakya

Department of Neurological Surgery, Kathmandu Medical College

Teaching Hospital, Sinamangal, Kathmandu

Correspondence : Dr Amit Thapa, Associate Professor, Department of Neurological Surgery,

Kathmandu Medical College Teaching Hospital, Sinamangal, Kathmandu

email: dramitthapa@yahoo.com

\begin{abstract}
Introduction and Objective: Repair of Brachial plexus injury is a neglected art in developing countries like ours. We discuss here various case scenarios managed at our centre and the challenges involved.

Materials and Methods: Cases with brachial plexus injury attending our OPD were included in this study. Different neurotisation and repair techniques were used depending on the situations. Outcome in form of improvement in function and relief of pain were evaluated.
\end{abstract}

Results: During last 5 year (July 2010 to September 2015), 100 patients with brachial plexus injury were evaluated in our outpatient OPD. Majority of them were too late to be offered any treatment. $20 \%$ patients had neuropraxia and were managed conservatively. 41 patients were operated. 19 were complete brachial plexus injury and underwent extraplexal neurotisation procedures. 11 were partial brachial plexus injury and had intraplexal neurotisation procedures. Neurolysis were done as required. 11 case of peripheral nerve injury was managed with direct repair and neurolysis. Almost all patients with neuropraxia had good recovery in follow up. Patients who underwent surgical intervention had good recovery in terms of recovery recovery of function and relief of pain.

Conclusion: Due to lack of awareness and socioeconomic reasons, majority of nepalese people approach very late for surgical options. Benefit of the brachial plexus repair depends upon factors like type of injury, timing of intervention, surgical technique and post operative follow up. We had good outcome in our patients who came early and continued on follow up.

Key words: Brachial plexus injury, neurotization, outcome 